\title{
The Diagnosis and Management of Urinary Tract Infection in Children: A Two Year Study in Army General Practice
}

\author{
Lt Col N J Grundy-Wheeler \\ MB, MRCGP, DA, RAMC \\ Station Medical Officer \\ Station Medical Centre, Hohne, BFPO 30
}

SUMMARY: A study of possible new cases of urinary tract infection in a population of some two thousand children under the age of twelve years is described. Over a two year period one hundred and four children were seen in the study and seventeen were found to have a significant bacterial infection.

Presenting symptoms, urinalysis results, investigation and methods of follow-up are examined. The results suggest that the incidence of detectable urinary system abnormality in children presenting for the first time with a proven urinary infection is less than in a comparable hospital population. In this study, of the seventeen children with proven infection, only four have so far been shown to have a detectable structural or functional abnormality.

\section{Introduction}

It has been said that 50 per cent or more of children who have a single proven urinary tract infection will have a demonstrable lesion in the renal tract ${ }^{1-3}$. This figure is neither widely accepted nor appreciated by general practitioners and is at least twice as high as most would anticipate ${ }^{4}$.

This survey sets out to examine whether the discrepancy represents a true hidden reservoir of children at risk being missed by general practitioners. It also attempts to identify different types of presentation of urinary infection in children and to assess the relative merits of protein and nitrite 'dipsticks' and subsequent laboratory reports on urine samples in aiding diagnosis.

\section{Method}

All children presenting with symptoms referable to the urinary tract and those with non-specific illness that could have represented occult urinary infection were included. A midstream specimen of urine (MSSU) was obtained at initial consultation in the majority of cases. A small number of MSSU's were collected the following morning after precise verbal or written instructions had been given to the parents. All children were examined for abdominal masses, abnormal genitalia or enlarged viscera, and each MSSU was tested for protein and nitrite prior to its being transported to the laboratory on the same day as collection. A separate card was completed for each child recording details of history, examination, urine testing, and the subsequent MSSU result. All cases of proven infection were followed up. A small number of babies with non-specific symptoms were included, and in these cases urine was collected by the 'clean catch' method. It was realised that this could be a potential source of error, but the more reliable method of suprapubic aspiration was not considered appropriate in a general practice setting.

The patients were allocated to one of three groups according to presenting symptoms:
Group 1. Symptoms referable to the urinary tract. Group2. Non-specific symptoms including abdominal pain or tenderness.

Group 3. Non-specific symptoms without abdominad

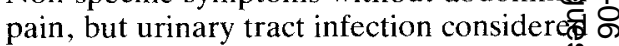
a possibility.

All children who had significant growth of organismi in a MSSU were treated with an appropriate antibiot for seven days, and allocated to one of two groups alternatively for further management.

Group A.

These children were followed up by th author at monthly intervals. Any furthe significant MSSU findings led to specialist investigation.

Group B.

$$
\begin{aligned}
& \text { These children were referred immedi- } \\
& \text { ately for specialist investigation and } \\
& \text { follow-up. } \\
& \text { Three very young children were ad- } \\
& \text { mitted to hospital for diagnostic radio- } \\
& \text { graphy. An Intravenous Pyleogram } \\
& \text { (IVP) and a micturating cystogram } \\
& \text { (MC) were performed in all these cases. }
\end{aligned}
$$

Results

Table 1 records the relationship between positive urine culture and demonstrable abnormality of the $\delta$ urinary tract. The results are broken down into the three presenting groups, and are further subdivided by sex and age.

Table 2 records the urinary tract abnormalities found.

Table 3 records the organisms cultured in the positive $\bar{N}$ MSSU's, while Table 4 compares results of bacterial 5 culture of urine with the results of urine testing by protein and nitrite 'dipsticks'. 
Table 1

Relationship between positive urine culture and demonstrable abnormality of the urinary tract

\begin{tabular}{|c|c|c|c|c|c|}
\hline & $\begin{array}{c}\text { Total } \\
\text { Number }\end{array}$ & $\begin{array}{c}\text { Male } \\
0-5\end{array}$ & $\begin{array}{l}\text { Male } \\
6-12\end{array}$ & $\begin{array}{c}\text { Female } \\
0-5\end{array}$ & $\begin{array}{c}\text { Fernale } \\
6-12\end{array}$ \\
\hline Group 1 & 19 & 3 & 2 & 10 & 4 \\
\hline $\begin{array}{l}\text { Positive MSSU }{ }^{*} \uparrow \\
\text { Demonstrable }\end{array}$ & 10 & 2 & 1 & 6 & 1 \\
\hline
\end{tabular}

Demonstrable

Abnormality

Group 2

Positive MSSU

Demonstrable

Abnormality

Group 3

Positive MSSU

$3 \quad 1$

Demonstrable

Abnormality

41

7

$\begin{array}{ll}6 & 7 \\ 4 & 0\end{array}$

0
7
0

0

$\frac{1}{10}$

(1)

0

1
44
0

$13-7$

0
7
0

18
1

\section{*MSSU-mid stream specimen of urine}

$\dagger$ Bacterial count reported as $>10^{5}$ organisms per millilitre of urine.

Notes:-

Group 1.

\section{Children presenting with symptoms suggestive} of urinary tract infection.

Over a two year period 104 children presented, 17 of whom proved to have growth from a MSSU. Four of these 17 have subsequently been shown to have a demonstrable abnormality in the urinary tract.

One presented clinically with an abdominal mass, and was found to have polycystic kidneys. The remaining sixteen were allocated alternately to general practice follow up or immediate hospital specialist referral. Two groups of eight were thus established. Those in the general practice group were followed up for an average of 14 months and had monthly MSSU examination. Two have now moved away, four are still under surveillance

Table 2

\section{Urinary tract abnormalities found}

\begin{tabular}{lc}
\hline Abnormality & Numbers \\
\hline Polycystic kidneys & $1^{*}$ \\
Vesico-ureteric reflux & $3 \dagger$ \\
\hline
\end{tabular}

*Abnormal intravenous pyclogram

$\dagger$ Abnormal micturating cystogram

Table 3

Significant organisms cultured in mid-stream specimens of urine

\begin{tabular}{lc}
\hline Organism & Number $(\%)$ \\
\hline Esch coli & $12(70 \%)$ \\
Streptococcus faecalis & $3(18 \%)$ \\
Proteus spp & $1(6 \%)$ \\
Mixed growth & $1(6 \%)$ \\
\hline Total & 17 \\
\hline
\end{tabular}

Group 2. Children with non-specific symptoms including abdominal pain or tenderness

Group 3. Children presenting with with non-specific symptoms not referable to abdomen.

and two, whose urine subsequently yielded significa bacterial growth, were referred for specialist care. Ote of these had proven reflex, but the other revealed na demonstrable abnormality. Both are currently on long term antimicrobial therapy under specialist review.

The immediate referral group of eight children w迎 reduced to six because two moved away before a. investigations had taken place. These remaining six \$l had IVP and MC performed. Two were found to hate reflux and the remaining four were apparently normal but they remain under MSSU surveillance. There wete more females than males in the study, but the proven abnormalities occurred in two boys and two girls.

The organisms grown (Table 3) were similar in type $\stackrel{\frac{\mathscr{Q}}{\complement}}{2}$ and frequency to those reported elsewhere 5.6 . From $\underset{F}{\Rightarrow}$ Table 4 it will be noted that the correlation between $\frac{0}{3}$ 'dipstick' findings and MSSU findings was much better for nitrite than for protein. It was noted, that there was however, much more observer variation in reading the protein 'dipstick' than the nitrite one.

\section{Discussion}

Most renal scarring occurs before the age of five years, and many older patients in need of renal transplant start down the road to renal failure with a single urinary tract infection in childhood. In view of this, and the author's observation that many patients' records contain evidence of an isolated urinary infection which has not, apparently, been followed up, it was decided to follow a protocol which combined a high index of suspicion with $\frac{7}{0}$ more careful follow-up. In this series, over 5 per cent of the population at risk presented during the two-year $N$ period and had their urine carefully collected and $N$ examined. Seventeen of the 104 cases studied were N 
found to have a urinary infection and four of these have been shown to have demonstrable pathology. The prevalence of demonstrable anatomical or functional abnormality associated with urinary infection was approximately $24 \%$. This figure correlates well with the expectations of most general practitioners, but is only half of that which might be expected by a specialist. This raises the question of whether a significant number of urinary infections is being missed in general practice, even when the index of suspicion is unusually high. It may be that the present routine investigations for detecting early renal tract lesions are not sensitive enough. of a napkin, may lead to the possibility of urinary infection being considered and to this diagnosis being confirmed by MSSU culture.

The management of first infections is crucial, and after the MSSU has been collected, treatment should be started as soon as possible. It is believed that the first infection in childhood causes the greatest damage to the kidney and its protective mechanisms ${ }^{8}$.

In this study in a general practice, the results of nitrite 'dipstick' testing correlated better with the findings of urine culture than did the results of the more commonly used protein test 'dipsticks'. This was especially true if the first voided morning specimen was used. False

Table 4

Comparison of the Results of Urine Culture with the Results of 'Dipstick' Testing

\begin{tabular}{|c|c|c|c|c|c|c|c|}
\hline & \multicolumn{2}{|c|}{$\begin{array}{l}\text { Protein } \\
\text { Dipstick }\end{array}$} & Total & \multicolumn{2}{|c|}{$\begin{array}{c}\text { Nitrite } \\
\text { Dipstick }\end{array}$} & \multicolumn{2}{|l|}{ Total } \\
\hline & Positive & Negative & & Positive & Negative & & \\
\hline All MSSU* & 21 & 83 & 104 & 19 & 85 & 104 & 0 \\
\hline Positive MSSU $†$ & 12 & 5 & 17 & 16 & 1 & 17 & $\frac{\pi}{\Phi}$ \\
\hline False Results & $9(43 \%)$ & $5(30 \%)$ & $14(13 \%)$ & $3(19 \%)$ & $1(6 \%)$ & $4(4 \%)$ & 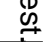 \\
\hline
\end{tabular}

*MSSU - midstream specimen of urine

$\dagger$ Bacterial count reported as $>10^{5}$ organisms per millilitre of urine.

There is debate about the value of an IVP in children under the age of five, but most paediatric specialists would hesitate to rely on a MC alone, because it may not demonstrate adequately the upper urinary tract ${ }^{6,7}$.

All the children in this survey who proved to have a significant urinary tract infection presented either with an illness clinically suggestive of this diagnosis or had some degree of abdominal pain or tenderness as a feature of their illness. The remainder, who had nonspecific symptoms without any abdominal component, produced no evidence of occult urinary tract infection when their MSSU's were cultured.

It is therefore worth stressing the need for careful history taking careful abdominal examination and proper urine testing in all such cases of vague abdominal pain or discomfort. It may well be that many initial urinary infections are missed in young babies because of the difficulty encountered in obtaining a proper MSSU specimen, but it is the author's experience that this problem can be overcome by careful explanation to the parents of what is required, and why it is required. Most babies with urinary infections present with fever and vomiting, and evidence of abdominal discomfort can often be elicited if the parents are asked the right questions. Abdominal examination requires much patience if sensitivity or resistance to pressure is to be demonstrated, but this finding, together with the smell negative reactions are usually due to incomplef incubation (less than three hours) ${ }^{9}$ although they mat occur in the presence of non-nitrite reducing bacterig which may be causative in up to 15 per cent of cases $^{4,10}:$

\section{Conclusion}

This small series indicates that good clinical practice and properly taken MSSU's will permit reliable diagnosis of urinary tract infection in babies and young children in general practice, and may lead to the early identification of anatomical or functional abnormalities of the urinary tract. Regular follow up is essential, and should include culture of a MSSU. The duration of follow up required is uncertain, and should be the subject of further study.

\section{REFERENCES}

1. Smellie $\mathbf{J} \mathbf{M}$, et al. Clinical and radiological features of urinary infection in childhood. $\operatorname{Br}$ Med $J$ 1964; 2: 12221226.

2. StAnsfield J M. Urinary tract infection in children: diagnosis and treatment in general practice. Practitioner 1977; 218: 59-64.

3. Cardiff Oxford Bacteriuria Study Group. Sequelae of covert bacteriuria in schoolgirls. Lancet 1978; 1: $889-894$.

\section{D}

○


4. Pots $S \mathrm{R}$ and IRwIN W G. Urinary tract infection in children: a survey of management. J $R$ Coll Gen Pract 1983;33: 353-355.

5. JOLly H. Diseases of Children. Fourth edition 1981. Blackwell Oxford.

6. GoDwin R J. Investigation of urinary infection in children. Update 1983; 26: 1597-1599.

7. JORDAN R M. Investigation of urinary infection in chil- dren. Update 1983;27: 1352.

8. WINBERG J. Urinary tract infection and reflux nephropathy in children. Medicine International 1982: 1101-1104.

9. ROY J B and WILKERSON R G. Fallibility of Griess (Nitrite) test. Urology 1984; 23. 3: 270-271.

10. Kunin C M. Detection, Prevention and management of Urinary Tract Infections. Third edition 1979, Lea and Febiger, Philadelphia. 